\title{
Route choice in the presence of a toll road: The role of pre-trip information and learning
}

\author{
Florian Knorr ${ }^{\mathrm{a}, *}$, Thorsten Chmura ${ }^{\mathrm{b}}$, Michael Schreckenberg ${ }^{\mathrm{a}}$ \\ a Physik von Transport und Verkehr, Universität Duisburg-Essen, 47048 Duisburg, Germany \\ ${ }^{\mathrm{b}}$ Nottingham University Business School, Nottingham, UK
}

\section{A R T I C L E I N F O}

\section{Article history:}

Received 10 March 2014

Received in revised form 1 September 2014

Accepted 2 September 2014

Available online 30 September 2014

\section{Keywords:}

Route choice

Laboratory experiment

Decision making

Experience

Toll road

\begin{abstract}
A B S T R A C T
Choosing a route is a complex task, especially since the roads' capacities are limited and road users non-cooperatively seek to optimize their own trip. This article present the results of three in-laboratory route choice experiments. In all experiments the participants had to choose repeatedly between a high-capacity toll-road and a toll-free main road. We investigate the role of pre-trip information on the resulting route usage dynamics. Besides the absence of a stable equilibrium point (Wardrop's User Equilibrium), we found that the participants improve their decisions over the course of time as a result of learning. Additional information appears only useful if only a limited number of participants possess such information. Moreover, we found gender-related differences in the observed road usage patterns: female participants were more likely to choose the toll road than male participants.
\end{abstract}

(c) 2014 Elsevier Ltd. All rights reserved.

\section{Introduction}

Driving a vehicle constantly requires making decisions: should I change lanes? is it safe to accelerate? which route is best for the home-to-work commute? The latter question is interesting for several reasons: Of course, to some extent it is a question of personal preference what constitutes a good trip (Albert, Toledo, \& Ben-Zion, 2011; Zhang \& Levinson, 2008). Yet, among the factors affecting the perceived trip quality 'travel time' has been found to be the most important one (Hall, Wakefield, \& Al-Kaisy, 2001; Papinski, Scott, \& Doherty, 2009). This quality measure is very intuitive as travel time is considered as "lost" time. This loss can even be quantified in money terms: an early study from 1999 (Small, Noland, Chu, \& Lewis, 1999) estimated the value of each hour traveled between \$2.6 and \$ 8.1. More recent studies (Brownstone \& Small, 2005; Cirillo \& Axhausen, 2006) estimate the value of travel time between $\$ 10$ and $\$ 20$ per hour. This range is consistent with the USDOT's guidance on the valuation of travel time in economic analysis (Belenky, 2011).

When travel time serves as the primary criterion to assess a trip, choosing the best route is a very difficult task. For the traffic conditions (e.g., free flow or congestion) change over time. Therefore, a currently uncongested road may be blocked when we finally reach it. Advanced traffic information systems (ATISs) such as on-board navigation devices might make things even worse. By providing information on the current traffic state and route capacities, congestion and travel times may increase instead of decrease-especially if the provided information is incomplete (Arnott, de Palma, \& Lindsey, 1991; Mahmassani \& Jayakrishnan, 1991; Noland, 1997). A congestion warning for a critical road segment, for instance,

* Corresponding author. Tel.: +49 203379 3901; fax: +49 2033796564 .

E-mail addresses: florian.knorr@uni-due.de (F. Knorr), thorsten.chmura@nottingham.ac.uk (T. Chmura), michael.schreckenberg@uni-due.de (M. Schreckenberg). 


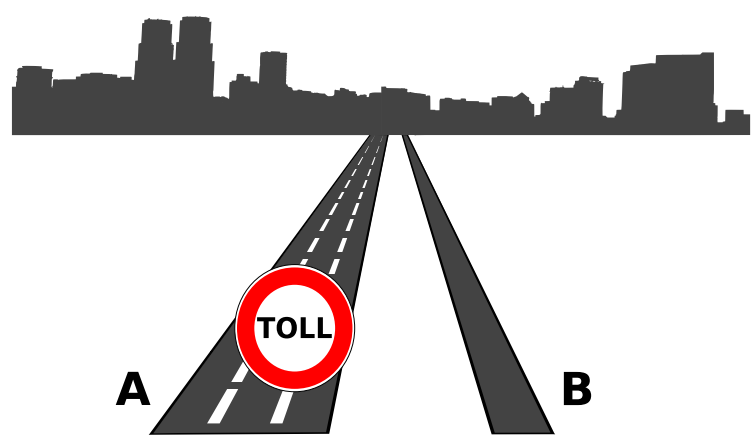

Fig. 1. The experiment from the participants' perspective. They were in the position of a tripmaker facing a commute downtown, and they could choose between a high-capacity toll-road (A) and a toll-free, low-capacity main road (B). The travel time on the selected road depends on the total number of participants choosing the same road.

may act as a self-destroying prophecy; when all drivers choose alternative routes to avoid the critical road segment, the latter may be free of congestion, whereas the alternative, formerly uncongested routes become congested.

A common approach to ease congestion is adding more capacity to congested corridors by adding more lanes to existing roads or by constructing new ones (Schrank, Lomax, \& Eisele, 2011). Modern approaches even envision the application of information and communication technologies for the same purpose (Knorr, Baselt, Schreckenberg, \& Mauve, 2012; Lakas \& Chaqfeh, 2010). These strategies can be combined with introducing tolls for the newly added infrastructure. In this context, it is interesting to ask how drivers react to such a route choice scenario. Do they find an "equilibrium" strategy of which road to use, and, if they do so, how long does it take to find such a strategy. Does additional information improve their choice?

Unfortunately, there is lack of empirical data investigating the impact of traffic information on route choice. A very common approach of collecting such data is by conducting commute surveys (Abdel-Aty, Kitamura, \& Jovanis, 1997; Mahmassani, Caplice, \& Walton, 1990; Mannering, Kim, Barfield, \& Ng, 1994). Thereby, the results represent rather a snapshot of the current situation. Therefore, its explanatory power in terms of the temporal evolution of decision processes, the role of learning, and the interaction between road users is quite limited. Besides, there is always the risk that the respondents adapt their answer to what they believe is right or favorable (cf. the halo effect) (Schofer, Khattak, \& Koppelman, 1993). Hence, laboratory experiments have become a valuable tool to study dynamics of the route choice process in a controlled environment (e.g., Helbing, Schönhof, \& Kern, 2002; Selten, Schreckenberg, Pitz, Chmura, \& Wahle, 2003, 2007). Furthermore, laboratory experiments offer the possibility of paying the participants and coupling their pay-off to the success of their decisions. This financial incentive makes laboratory experiments much closer to reality because in reality a bad route choice costs time and/or money, too. ${ }^{1}$

In this article we want to investigate the influence of traffic information on route choice behavior by presenting the results of three laboratory experiments-each with more than 100 participants. In all experiments the participants had to choose repeatedly between two routes, a so-called main road and a toll road. Yet, the information provided to the participants before making their choice varied. Similar to Selten, Chmura, Pitz, Kube, and Schreckenberg (2007), the participants were assigned a fixed starting balance, and they lost the more money the more participants chose the same road. Naturally, selecting the toll road led to an additional, demand-independent fee. The benefit of the toll road was that it had a higher capacity and, therefore, an increased demand resulted in a slower increase of the resulting travel time and expenses.

\section{Experimental setup}

The experiment, which was programmed and conducted with the software z-Tree (Fischbacher, 2007), mimicked a realistic route choice scenario (The participants' instructions can be found in Appendix A): all participants were assigned to role of motorists who repeatedly had to travel to the same destination (e.g., the home-to-work commute). For their trip, they could choose between two roads-a toll road and a toll-free main road (see Fig. 1). The toll serves here as a deterrent ${ }^{2}$ to choose this road (de Palma \& Lindsey, 2000). (In the context of congestion pricing, such deterrent effects are used to control

\footnotetext{
${ }^{1}$ Before designing our experiments, we have contacted a company operating a German toll road, and we asked for their experience with surveys. They told us that they used surveys before opening the toll road to determine (a) how many respondents would be willing to use the new toll road, and (b) which price they would be willing to pay. After the opening of the toll road, significantly less drivers than expected used the toll road as the hypothetical situation of a survey did not compare to the actual situation of choosing the toll road. Hence, the monetary gains/losses in our experiments are a very important aspect regarding the results' transferability to reality.

In this context, however, it has to be noted that the participants of our experiments received a starting balance from which the travel expenses were deducted. Therefore, the participants left the experiment with more money than they started with, whereas in real life travel expenses are unavoidable and actual "losses".

${ }^{2}$ Although tolling makes a road less attractive to drivers, this does not mean that the public opinion is per se against tolling and road pricing. The analysis of international surveys on road pricing and tolling (Kriger, Shiu, \& Naylor, 2006) revealed a more sophisticated public opinion.
} 
traffic by time-varying charges (Small \& Gomez-Ilbanez, 1998; Ieromonachou, Potter, \& Warren, 2006). In our scenario, where there is a parallel toll-free road, drivers are known to be very price-sensitive (Victoria Transport Policy Institute, 2014).).

After each period, the participants' starting balance was charged by an amount proportional to the travel time on the selected road. Moreover, they had to pay a constant amount of 30 currency units (30 euro cents) if they decided to use the toll road. The participants knew that the travel time on either road increased with the number of participants choosing the corresponding road, but they did not know the exact relation between road usage and resulting travel expenses. The only additional information was that, with an equal number of travelers on both roads, the main road was cheaper.

In each realization of the experiment eight-teen participants simultaneously had to choose repeatedly one of the two roads. In each period, the situation was identical to the first period. However, the following information was provided for all previous periods: the participant's route choice in the corresponding period, the number of participants on either road, and his/her current balance.

To study the influence of real-time pre-trip information we performed three slightly different experiments. A common feature of all experiments is that the participants had $30 \mathrm{~s}$ to decide which route to take in each period. (The participants were told that, if they did not make their decision within in this time, the toll road was automatically selected). ${ }^{3}$

- In experiment $\mathbf{A}$ a period ended after all participants had selected a road.

- In experiment B, all participants entered a second step after they had made their route choice. In this second step they were informed on how many participants intended to take either route, and they were offered the possibility to alter their initial choice. Again, they had $30 \mathrm{~s}$ to confirm or to alter their initial choice. (After $30 \mathrm{~s}$ the initial choice was automatically confirmed.)

- Experiment C was similar to experiment B, but the participants had to pay 6 currency units (6 euro cents) to enter the second step.

There are intuitive interpretations for all of the just described experiments. Experiment A obviously represents the case were drivers have no information on the traffic state on either road. Hence, their only guide to choose a road is their experience which they gain by repeatedly deciding for one road and learning about the resulting travel expenses. In experiment $B$, all participants simultaneously get identical information on the intended road usage of all participants and have the possibility to correct their choice. One can think of this information as traffic information broadcast by radio. In this scenario, drivers can react to this message by choosing an alternative route. Yet this strategy is only promising if not too many drivers react this way. Due to the associated fee in experiment $C$, just a few participants are expected to make use of the additional information and alter their route choice. This may correspond to the situation where drivers use (partly fee-based) services of personal navigation devices to include real-time traffic information in their route planing. In this sense, experiment $C$ can be understood as a mixture of A and B as some drivers have additional information on the level of service on either route, whereas the others have to completely rely on their experience.

\subsection{Travel times and equilibrium states}

As already stated, in each experiment $n_{p}=18$ participants interacted with each other. Let $n_{\text {toll }}$ and $n_{\text {main }}=n_{p}-n_{\text {toll }}$ denote the number of participants choosing the toll road or the main road, respectively. The resulting travel times on the main road $t_{\text {main }}$ and on the toll road $t_{\text {toll }}$ followed from the equations

$$
\begin{aligned}
& t_{\text {toll }}=n_{\text {toll }}, \\
& t_{\text {main }}=3 n_{\text {main }},
\end{aligned}
$$

and the resulting travel expenses for either road, $c_{\text {toll }}$ and $c_{\text {main }}$, were given by

$$
\begin{aligned}
& c_{\text {toll }}=30+t_{\text {toll }}, \\
& c_{\text {main }}=t_{\text {main }} .
\end{aligned}
$$

By comparing Eqs. (1) and (2), one can see that the travel time on the main road grows stronger than on the toll road with additional participants on the corresponding road. Therefore, one can think of the toll road as a multi-lane roadway which can satisfy a higher traffic demand than the one-lane main road.

For $n_{\text {toll }}=6$ and $n_{\text {main }}=12$ the travel expenses on both routes are identical in our scenario. This distribution corresponds the "user equilibrium" (UE) according to Wardrop's first principle (Wardrop, 1952) as travel expenses are the only quality measure in our experiments. (From a game theoretic point of view, one may also call any such configuration a pure-strategy Nash Equilibrium.) This means that no participant can lower his/her travel expenses by changing his/her choice if all other participants keep their initial choice.

The linear relation of Eqs. (1) and (2) deserve some critical comments: Traffic is a dynamical system, and travel times show non-linear behavior-at least in certain density regimes (Kerner, 2004). Therefore, complex mathematical models have

\footnotetext{
${ }^{3}$ By choosing the toll road as the default road, we wanted to "force" the participants to actively choose one road, as they knew that the toll road will cost them at least 0.30 euro. Indeed, in more than $99 \%$ of all cases the participants made their choice before the timeout.
} 
been developed to relate traffic flow and travel time (Singh \& Dowling, 1999). Such models assume the existence of a deterministic relation between the observables. This is a valid assumption when the flow rates are sufficiently small. At higher flow rates, however, a traffic breakdown can occur spontaneously (i.e., stochastically) on at least one of the roads. It was recently shown (Kerner, 2013) that, when the probability of a traffic breakdown is greater than zero, then, instead of Wardrop's principles, a breakdown minimization (BM) principle (Kerner, 2011, 2014) should be used for a route choice. Hence, it is evident that our linear travel time functions (1) and (2) are a simplification of reality. Despite their simplicity, they capture the most important aspects of the travel time - road usage relation:

- With few drivers choosing a specific road, the vehicle density on this road is low, and the resulting average speed is high. This results in low travel times.

- When more and more drivers choose the same road and, thereby, increase the vehicle density, they start hindering each other. This lowers the average speed and increases the travel time for all drivers.

So, from the participants' perspective, who did not know the exact travel time function (see Appendix A), the relation between road usage and travel time was consistent with their own travel experiences.

\subsection{The participants}

For each experiment we performed six independent realizations (each with 18 participants). The participants were mostly students of the Universities of Düsseldorf and Duisburg-Essen, Germany, where the experiments were conducted. Due to the generally comprehensible design of the experiments, the participants were not required to possess a driver's license. Additional information on the participants are given in Table 1.

\section{Results}

As all experiments were repeated six times, the following results show the average values of all repetitions or of all participants, respectively.

\subsection{Road usage and choice variability}

First, we study the temporal evolution of the number of participants choosing the main road $n_{\text {main }}$. Remember that the UE (or Nash equilibrium) is at $n_{\text {main }}=12$, what the participants did not know at the start of the experiment. Therefore, the largest deviation from this equilibrium value can be observed during the first few periods (see Fig. 2(a)). There is, however, a general tendency in all experiments to approach the equilibrium value over the course of 50 periods. During the first ten periods of the experiments, on average 10.9 participants chose the main road, whereas this number increased to 11.6 for the last ten periods. This observation cannot be explained by random fluctuations. (The $H_{0}$-hypothesis that the proportion of participants choosing the main road in periods one to ten and 41 to 50 is identical can be rejected on a 99\%-confidence level.) For better visibility, we have added a blue trend line resulting from linear regression to Fig. 2(a). The trend lines, which do not imply a linear relation, indicate that the equilibrium value is approached from smaller values $\left(n_{\text {main }}<12\right)$. This could be expected as the toll road causes a smaller loss per additional road user for participants choosing this road. Hence, it is more favorable to choose the toll road when in doubt which route to choose.

The tendency to approach $n_{\text {main }}=12$ suggests that the participants organized themselves to find the equilibrium distribution between the two routes. The benefit of experience and learning reflects itself not only in the approach of the equilibrium value $n_{\text {main }}=12$ but also in a decrease of fluctuations between both routes. Fig. 2(b) shows the standard deviation (SD) of the number of participants choosing the main road. Similar to Fig. 2(a), the largest values of the SD are observed during the first few periods before the participants gathered sufficient information about the available routes. But the experiments' SDs distinguish in their absolute values. In experiment A they are in general larger than in experiment $B$, and those of experiment $B$ are larger than those of experiment $C$ (averaged over all 50 periods: $\left.\mathrm{SD}_{A}=2.17, \mathrm{SD}_{B}=1.75, \mathrm{SD}_{C}=1.44\right)$. This suggests that the intermediate step of experiments $\mathrm{B}$ and $\mathrm{C}$, where participants can change their initial choice, allows for a better coordination between participants. Fig. 3 confirms this assumption. It shows the average number of participants who changed their initial choice in each period. Obviously, this number is lower

Table 1

Overview of the participants.

\begin{tabular}{|c|c|c|c|}
\hline Property & Experiment A & Experiment B & Experiment $\mathrm{C}$ \\
\hline Gender (Male/Female) & $45 / 63$ & $55 / 53$ & $46 / 62$ \\
\hline Driving license (Yes/No) & $99 / 9$ & $102 / 6$ & $89 / 19$ \\
\hline Average age & $24.2^{\mathrm{a}}$ & 23.4 & 24.6 \\
\hline
\end{tabular}

a The age of one participant was erroneously recorded as 100 years. We have removed this data set before calculating the average age. 


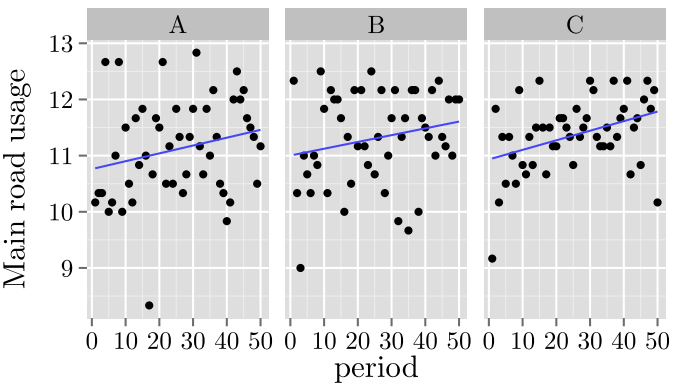

(a)

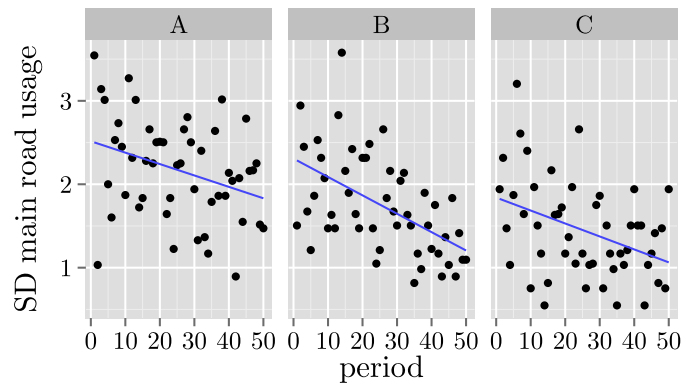

(b)

Fig. 2. (a) Average number of participants choosing the main road per period and (b) the corresponding standard deviation (SD) per period grouped by experiment. For better readability and comparability, we have added the blue line indicating a linear trend. (It is not suggested that there actually exists a linear relation.) (For interpretation of the references to color in this figure legend, the reader is referred to the web version of this article.)

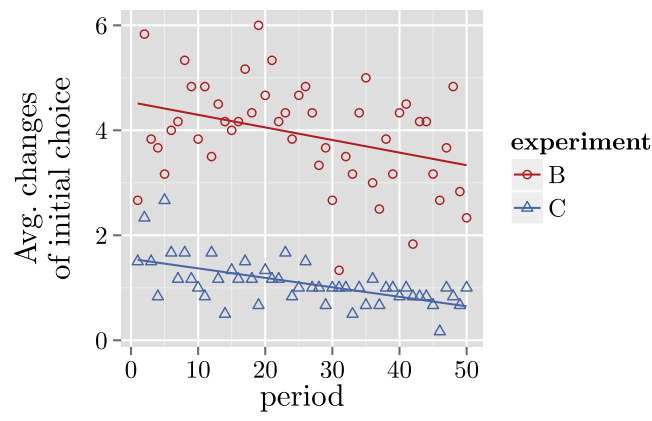

Fig. 3. The figure shows the average number of participants who changed their initial choice per period. (This was only possible in experiments B and C. The trend lines do not suggest an actual linear relation.)

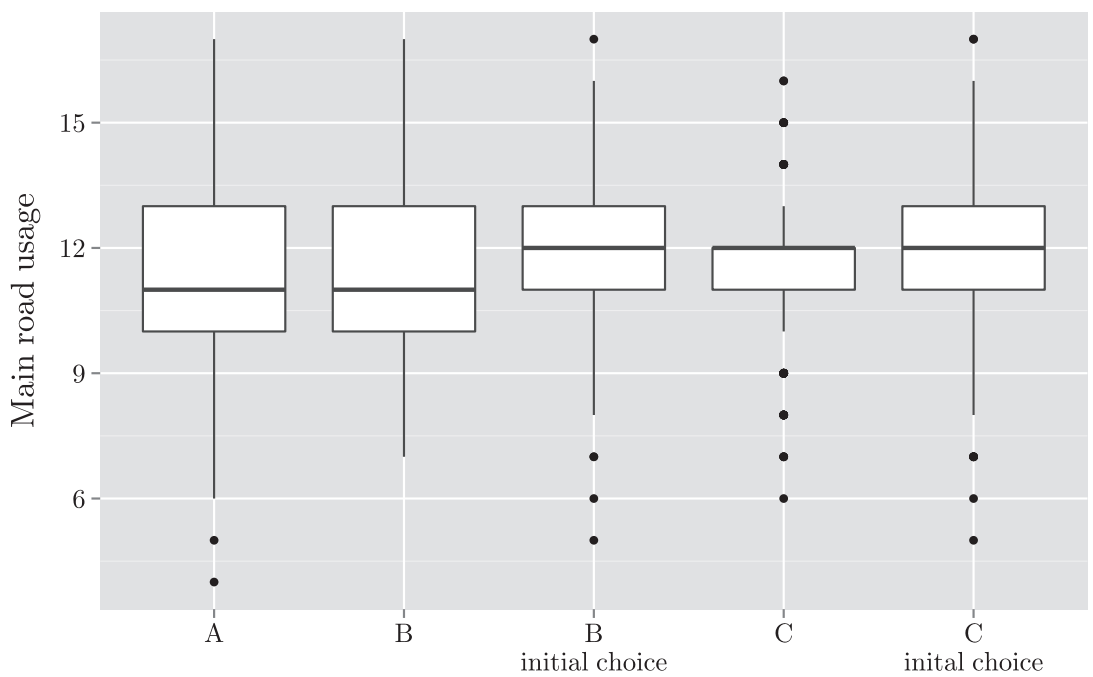

Experiment

Fig. 4. The box plot shows the distribution of main road user over 50 periods grouped by experiment. For experiments $\mathrm{B}$ and $\mathrm{C}$, the plot also shows the distributions that one would have obtained if the participants were not offered the possibility to change their initial choice.

for experiment $C$ as participants had to pay for the possibility to change their choice. (On average only 2.36 participants entered the intermediate steps per period in experiment C.) In later periods, it is probably considered less advantageous to alter the initial route choice as the participants gain more experience.

A better insight in the effect of the intermediate steps offers Fig. 4. It shows the number of main road users for each experiment and, for experiments B and C, also the hypothetical number of participants choosing the main road, if they had stuck to 


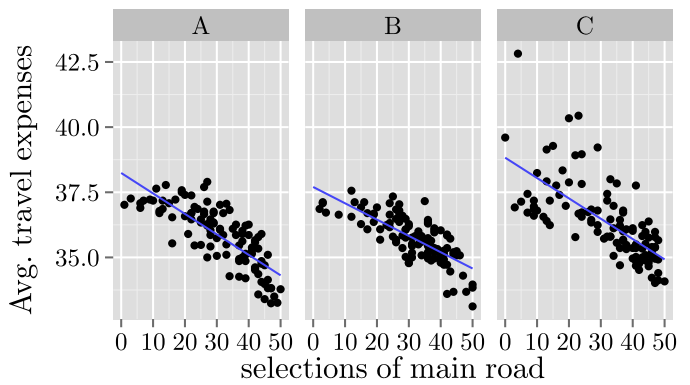

(a)

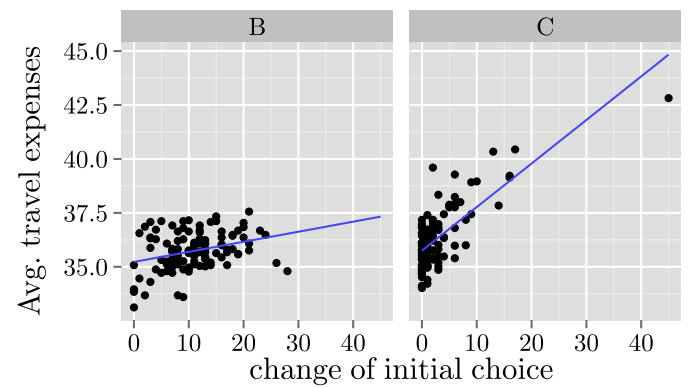

(b)

Fig. 5. (a) The participants' average travel expenses per period depending on the number of main road selections. (b) For experiments B and C, the average travel expenses per period depending on the number of changes of the initial choice. For better readability and comparability, we have added blue lines indicating a linear trend. (It is not suggested that there actually exists a linear relation.) The slope of the blue trend line of experiment $\mathrm{C}$ is much steeper than for experiment $\mathrm{B}$, as the participants had to pay for the possibility to change their choice in experiment $\mathrm{C}$. (For interpretation of the references to color in this figure legend, the reader is referred to the web version of this article.)

their initial choice. A comparison between experiments A and B shows that the observed distributions are nearly identical. During the initial choice steps in experiments B and C, however, the participants chose the main road more frequently. Moreover, there is no difference in the distribution of the initial choice for experiments B and C. But the final distribution after the intermediate step is very different for these two experiments: in experiment $C$, there are only very few periods in which more than twelve participants choose the main road.

This can be explained as follows: With the additional fee to enter the intermediate step in experiment $\mathrm{C}$, only few participants make use of this opportunity. Thereby, they know that they can effectively control the resulting distribution with their own actions. Altogether, this leads to a very small number of periods where more than twelve participants simultaneously decide to choose the main road. This number is actually significantly lower in experiment $C$ compared to experiments $\mathrm{A}$ and $\mathrm{B}$, respectively. $\left(\mathrm{H}_{0}\right.$-Hypothesis: "The proportion of periods with more than twelve participants choosing the main road is equal in experiments C and A (or B)." This hypothesis can be rejected on a 99\%-confidence level with a $p$-value of less than 0.0016 (or 0.0038).).

\subsection{Individual choices: Successful, unsuccessful, and gender-specific strategies}

In all experiments the primary concern of the participants was to reduce their own expenses. To do so, there were several strategies to reach this goal (e.g., they could frequently change their initial choice, or they could constantly prefer one route over the other). In the following, the success of such strategies is measured in terms of the subjects' total travel expenses. As one can see from Fig. 5, the participants' travel expenses increased the more frequently the toll road was used and the more often the initial choice was changed. In other words, the best strategy for a participant was to choose the main road and to stick with this choice. This is very well illustrated by Table 2 which shows the characteristics of the 18 participants with the lowest and highest travel expenses in each session of the three experiments.

Finally, we investigated whether there were any gender-related characteristics with respect to the participants' behavior. Table 3 shows how often male and female participants selected the toll road, how often they changed their initial choice, and how often they entered the intermediate step in experiment $\mathrm{C}$. Regarding the adherence to the initial choice, we did not found statistical evidence that there was a gender-related difference in changing the initial choice. Similarly, there was no evidence for any gender-related preferences for entering the intermediate step in experiment C. Surprisingly, female participants chose the toll road significantly more often than their male counterparts. $\left(H_{0}\right.$-Hypothesis: "There is no difference in the frequencies of selecting the toll road between male and female participants." This hypothesis can be rejected on at least a 97.5\%-confidence level (for experiments A and C even on a 99\%-confidence level). The corresponding $p$-values ranged from less than $10^{-8}$ in experiment $C$ to 0.016 in experiment B.) Despite the female participants' greater affection for the toll road, the average travel expenses of male and female participants did not differ significantly. (Nevertheless, the average expenses of male participants were lower in all experiments.) Other factors than the participants' sex to explain the observed behavior are unlikely due to the relative homogeneity of the group of participants. As they were mostly students, they had approximately the same age and a similar educational background. ${ }^{4}$

\section{Discussion}

In all experiments, we could observe that the participants modify and change their behavior based on the information they gather in the course of the experiment (Fig. 2(a)). This is exactly the definition of learning. Hence, learning allows them

\footnotetext{
${ }^{4}$ Of course, one can think of other socio-economic factors (e.g., personal wealth) that might also influence the participants' choice.
} 
Table 2

The choices made by the participants who performed best in each session compared to the ones who had the highest travel expenses. The number in the fourth and fifth columns indicates how often the participant actually changed his/her initial choice. For experiment $\mathrm{C}$, the corresponding number in brackets gives the number of times the corresponding participant entered the intermediate step where he/she could change his/her initial choice. Remember that entering this step cost 6 currency units each time.

\begin{tabular}{|c|c|c|c|c|c|c|}
\hline \multirow[b]{2}{*}{ Experiment, session } & \multicolumn{2}{|c|}{ Total cost } & \multicolumn{2}{|c|}{ Changed initial choice } & \multicolumn{2}{|c|}{ Toll road selection } \\
\hline & Best & Worst & Best & Worst & Best & W orst \\
\hline A, 1 & 1663 & 1879 & $\mathrm{n} / \mathrm{a}$ & $\mathrm{n} / \mathrm{a}$ & 1 & 31 \\
\hline A, 2 & 1701 & 1889 & $\mathrm{n} / \mathrm{a}$ & $\mathrm{n} / \mathrm{a}$ & 5 & 36 \\
\hline A, 3 & 1689 & 1869 & $\mathrm{n} / \mathrm{a}$ & $\mathrm{n} / \mathrm{a}$ & 0 & 28 \\
\hline A, 4 & 1675 & 1863 & $\mathrm{n} / \mathrm{a}$ & $\mathrm{n} / \mathrm{a}$ & 2 & 47 \\
\hline A, 5 & 1662 & 1882 & $\mathrm{n} / \mathrm{a}$ & $\mathrm{n} / \mathrm{a}$ & 3 & 39 \\
\hline A, 6 & 1735 & 1895 & $\mathrm{n} / \mathrm{a}$ & $\mathrm{n} / \mathrm{a}$ & 5 & 23 \\
\hline $\mathrm{B}, 1$ & 1698 & 1878 & 0 & 21 & 0 & 38 \\
\hline $\mathrm{B}, 2$ & 1750 & 1858 & 7 & 10 & 19 & 15 \\
\hline $\mathrm{B}, 3$ & 1692 & 1856 & 0 & 15 & 0 & 34 \\
\hline B, 4 & 1736 & 1852 & 5 & 20 & 8 & 23 \\
\hline B, 5 & 1715 & 1867 & 3 & 15 & 3 & 25 \\
\hline$B, 6$ & 1656 & 1856 & 0 & 5 & 0 & 47 \\
\hline C, 1 & 1740 & 1964 & 0 & $6(20)$ & 5 & 35 \\
\hline C, 2 & 1701 & 2141 & 0 & $45(48)$ & 3 & 46 \\
\hline C, 3 & 1738 & 1946 & 0 & $9(18)$ & 8 & 28 \\
\hline C, 4 & 1704 & 2022 & 0 & 17 (39) & 0 & 27 \\
\hline C, 5 & 1769 & 2017 & 0 & $13(30)$ & 3 & 30 \\
\hline C, 6 & 1706 & 1980 & 0 & $2(23)$ & 2 & 50 \\
\hline
\end{tabular}

Table 3

The participants' choices by sex.

\begin{tabular}{|c|c|c|c|c|c|c|}
\hline & \multicolumn{2}{|c|}{ Experiment A } & \multicolumn{2}{|c|}{ Experiment B } & \multicolumn{2}{|c|}{ Experiment C } \\
\hline & Females & Males & Females & Males & Females & Males \\
\hline Changed initial choice & $\mathrm{n} / \mathrm{a}$ & $\mathrm{n} / \mathrm{a}$ & 561 & 616 & 175 & 152 \\
\hline Selected toll road & 1295 & 770 & 1028 & 979 & 1247 & 743 \\
\hline Total number of route choices & 3150 & 2250 & 2650 & 2750 & 3100 & 2300 \\
\hline Entered intermediate step & $\mathrm{n} / \mathrm{a}$ & $\mathrm{n} / \mathrm{a}$ & $\mathrm{n} / \mathrm{a}$ & $\mathrm{n} / \mathrm{a}$ & 397 & 312 \\
\hline Average total travel expenses & 1802 & 1775 & 1794 & 1780 & 1825 & 1809 \\
\hline
\end{tabular}

to come close to (but not reach) the UE. In addition, the growing experience manifests itself in the decrease of the standard deviation of the main road's usage (Fig. 2(b)). Consequently, the participants do not only have a good idea of the equilibrium value, but they also become more and more confident of how to achieve it. This confirms results of earlier studies (Adler \& McNally, 1994; Adler, 2001; Yang, Kitamura, Jovanis, Vaughn, \& Abdel-Aty, 1993) that found learning/experience being a very essential factor in the route choice process.

Although experience drives the participants towards the UE, fluctuations occur even after 50 periods and a true convergence to the UE was not reached. On might object 50 periods are not enough for true convergence to be reached. However, in a related experiment consisting of 200 periods a similar behavior was observed (Selten et al., 2007). These findings and related results (Helbing et al., 2002; Meneguzzer \& Olivieri, 2013; Selten et al., 2003) suggest that Wardrop's UE should be considered as an idealized concept which can only approximately be reached in reality. Besides, there are other destabilizing effects in reality regarding a stable equilibrium (e.g., road works, accidents, weather). These effects, which we did not consider in our experiments, are additional obstacles towards a steady state. Our conclusions are in complete agreement with Iida, Akiyama, and Uchida (1992) and Mannering who wrote (Mannering, 1989): “Most existing research work assumes the existence of traffic equilibrium or, in the case of research on commuter dynamics: the existence of a steady state. [...] due to random incidents (vehicle breakdowns, weather, and so on) and/or changing commuter tastes and perceptions of congestion, a 'true' equilibrium is not realistically achievable and a steady state will be, at best, unstable, or, more likely, will not even exist."

Our slightly varied experiments allow several statements on the role of pre-trip information. As Fig. 4 shows, only minor differences in the road usage between experiments A and B could be observed. Originally, one might have expected that the participants could use the intermediate "change-the-initial-choice" step for better coordination with each other. But it seems that in experiment B the participants used their initial route choice to make a less deliberate decision as they knew they could change it without any drawbacks. Only in experiment $\mathrm{C}$, where a limited number of participants decided to enter the intermediate step (due to the associated additional fee), a better coordination and a more effective usage of the two roads could be observed. Here, for most participants their initial route choice was also their final choice. Consequently, the participants entering the intermediate step could assume that the information that they receive in this step will not change (much) 
Table 4

Average travel expenses per period and the corresponding standard deviation (SD) for either road grouped by experiment. (For better comparability, the given travel expenses do not include the additional fee for entering the initial step in experiment C.)

\begin{tabular}{|c|c|c|c|c|c|c|}
\hline & \multicolumn{2}{|l|}{ Experiment A } & \multicolumn{2}{|l|}{ Experiment B } & \multicolumn{2}{|l|}{ Experiment $\mathrm{C}$} \\
\hline & Avg. expenses & SD & Avg. expenses & SD & Avg. expenses & SD \\
\hline Main road & 34.70 & 6.48 & 34.86 & 5.50 & 34.74 & 4.53 \\
\hline Toll road & 37.61 & 2.17 & 37.22 & 1.82 & 37.00 & 1.57 \\
\hline
\end{tabular}

unless they change their own route choice. This suggests that the benefit of additional information pays out only if not all participants have access to this information. Overall, these findings give empirical evidence to computational results (Arnott et al., 1991; Ben-Akiva, De Palma, \& Isam, 1991; Noland, 1997) that have questioned the benefit of additional information for the route choice. Arnott et al. (1991), for instance, concluded: "While a single driver can benefit from proprietary information, when all drivers are informed they may end up worse off." Similarly, Emmerink, Axhausen, Nijkamp, and Rietveld (1995) found that additional information is beneficial only if the share of informed drivers does not exceed $20 \%$.

One of the most surprising results of our experiments was the strong preference of female participants for the toll road. As there was obviously no incentive to choose this road (the additional fixed user fee for the toll road might actually have been considered as a repellent), we expected no difference in the proportions of males and females choosing either road. It is, however, well-known that socioeconomic factors such as age, sex, or average income can influence the route choice and related aspects (e.g., shift of departure time, influence of traffic information) (Adler \& McNally, 1994; Mannering, 1989; Mannering et al., 1994). Emmerink, Nijkamp, Rietveld, and van Ommeren (1996) found that women were more reluctant to change their choice by traffic information. They suggested that women are more risk-averse than their male counterparts with respect to their route choice.

Such an affinity of women to avoid risks can be observed in various situations-not only in the context of route choice: Numerous articles (see the review article by Croson \& Gneezy (2009) and its critical discussion (Nelson, 2012)) found a general tendency of women to avoid risks and competition in economics experiments and data from naturally occurring markets. This general behavioral pattern might explain our own findings as well: Assuming women are more risk-averse, we expect the reliability of a route (in terms of travel expenses and travel time) to be very important to them. In our experiments, the toll road fulfilled this requirement because fluctuations in its number of users caused lower fluctuations in the resulting travel expenses (see Eqs. (3) and (4)). Thus, the fluctuations in the experienced travel expenses are considerably less pronounced on the toll road than on the main road (see Table 4).

It is important to note that such a preference has already been found in real world scenarios: Lam and Small (2001) analyzed data from a mail survey and from traffic loop detectors of State Route 91 in Orange County, California. The commuters on this route could choose between a variably tolled route and a free one. They found that the toll road was more attractive to women than to men. Women also attached much more importance to travel time reliability. Brownstone and Small (2005) supposed this followed from the women's reduced scheduling flexibility due to more child-care responsibilities. Based on our own results we can reject this explanation for two reasons: (i) All participants of our experiments were informed of the amount of time required to complete the experiment, and choosing the toll road did not result in time savings. (ii) Due to the relative young age of our participants, we doubt that many of the female participants were involved in child-care. The study of Brownstone and Small, however, provides further evidence for that women have a higher preference for toll roads than men. In their study they evaluated two road pricing demonstrations in southern California (State Route 91 and Interstate 15).

\section{Conclusions}

In this article we have presented the results of three closely related laboratory experiments investigating route choice behavior and the role of information. The identical general setup of the experiments allows a better comparability and facilitates to draw meaningful conclusions.

We admit that we simplified our experiments in some aspects. In these experiments, the travel expenses were the only criterion by which the participants could assess the success of their route choice. In reality, the decision which route to take typically is a multi-objective decision-making process. In addition to the travel time and expenses, travel time reliability, number of intersections/traffic lights, congestion probability, or the road categories (highway vs. arterial road) are other aspects that possibly need to be taken into account (Papinski et al., 2009). Moreover, there are other ways to minimize travel time. By choosing different departure times, commuters can directly influence the congestion probability and the travel time on their route (see Mahmassani, Chang, \& Herman (1986) for an experiment). In our experiments travel time and expenses were directly correlated. As travel time is the most important criterion among the aforementioned ones, our results can be easily transferred to real-world route choice scenarios.

We have seen that the road usage patterns are dynamic: drivers interact with each other, they evaluate their travel expenses and adapt their behavior. This might be the reason for the clear differences between stated preference (i.e., response to hypothetical choices) and revealed preference (i.e., response to actual choices) studies in the literature (Brownstone \& Small, 2005). 
We summarize our major findings as follows:

- Even after 50 periods, we could not observe a stable distribution of the participants among the available roads. Therefore, we doubt the existence of a stable equilibrium point such as Wardrop's User Equilibrium.

- Learning and experience play important roles in the route choice process. From this follows that stated preference studies to determine road usage patterns offer only limited insight.

- Supplying identical information to all road users does not yield significant benefit to them.

- A better road usage can be achieved, however, if only few participants possess additional information.

- Female participants were found to prefer the toll road, which offered more reliability in terms of the resulting travel expenses. It seems that women, in general, prefer reliability and seek to avoid the risk of losing time or money by a bad route choice. (Thereby, they also pass on the possibility to save time or money.)

What are the practical consequences of our findings? The non-existence of stable equilibrium points (UE) in traffic networks requires more sophisticated approaches regarding traffic assignment and traffic network analysis. Approaches relying on Wardrop's principles should be considered as insufficient. In the light of our findings, we believe that the already mentioned breakdown minimization (BM) principle (Kerner, 2011, 2014) is much better suited to analyze traffic networks.

In addition, we have seen that, besides travel expenses and travel time, the reliability of a route is also an important aspect in the route's assessment. Hence, a constant level of dense or viscous traffic might be more favorable than unpredictable transitions from free to congested traffic. This should be considered in future traffic control applications.

Finally, we can conclude that the concepts of traffic information distribution should be reconsidered. As we have seen, road usage can be improved, if only few participants possess additional information. Therefore, we expect better possibilities of traffic control by providing a share of drivers with no or even wrong (e.g., travel times or congestion warnings) traffic information.

Our findings may also contribute to the development of better mathematical and computational models mimicking the route choice process. In this context, we suggest that one should prefer such models that involve learning components (Nakayama \& Kitamura, 2001; Cascetta \& Cantarella, 1991; Ozbay, Datta, \& Kachroo, 2001; Jha, Madanat, \& Peeta, 1998) and that one should refrain from models showing perfect convergence towards a stable steady state (e.g., (Mahmassani \& Jayakrishnan, 1991)).

\section{Acknowledgments}

The work was funded by Deutsche Forschungsgemeinschaft (German Research Foundation, DFG) under Grant No. SCHR 527/5-1. We thank Dominik Wegerle, Benedikt Piekorz, Christoph Helbach, and Volker Benndorf for assistance in conducting the experiments.

\section{Appendix A. Participants' instructions}

The following subsection is a translation of the instructions that the participants received at the begin of each experiment. (To some extent the translation was shortened. For example, the rules of conduct in the laboratory (e.g., no eating) are not printed.)

\section{A.1. Experiment's instructions}

In today's experiment, you are part of a group consisting of 18 participants. The experiment's setup is identical for all participants.

- The experiment consists of 50 periods.

- In each period you will act as a motorist who has to travel from an origin $A$ to a destination $B$. To travel from $A$ to $B$ you can either choose the "main road" or the "toll road" (see Fig. A.6).

- The travel expenses for the trip from $A$ to $B$ satisfy the following conditions: The travel expenses on both roads increase with an increasing demand, and they decrease with a decreasing demand. With an equal demand on both roads, the travel expenses on the main road are lower than on the toll road.

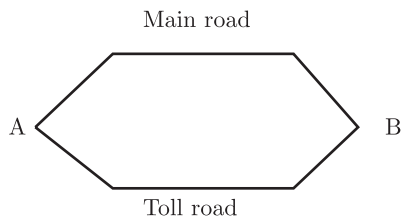

Fig. A.6. Schematic sketch of your choice to travel from A to B. 


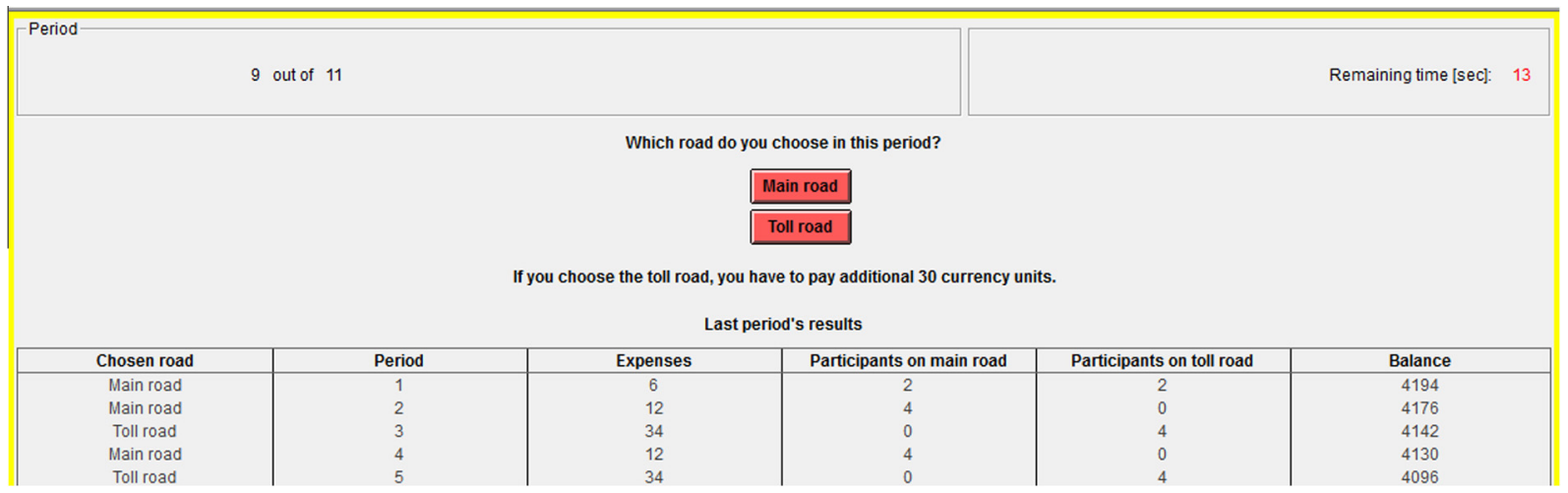

Fig. A.7. User screen requesting to choose a road.

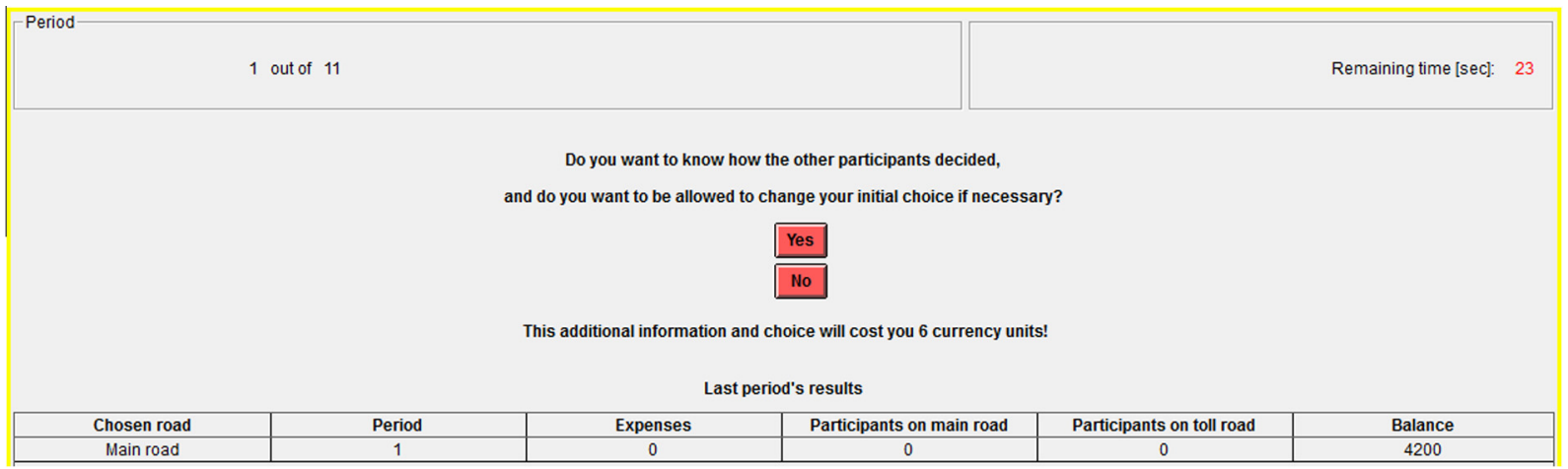

Fig. A.8. User screen offering to change the initial choice.

- After each period, you have to choose between the two roads again. (see Fig. A.7; numerical values are fictitious)

- Each participant receives an initial balance of $x$ Taler. ${ }^{5}$ One Taler corresponds to 0,01 euro.

- You do not play against a computer simulation, but you interact with the other participants. A new period starts, after all participants have made the necessary decisions.

- To answer the question you have $30 \mathrm{~s}$. If you do not press a button within this time, the toll road is automatically selected.

The following item was part of the instructions of experiment $\mathrm{C}$.

- After you have made your route choice, you are offered the possibility to acquire information on how the other participants decided. In this case, you have the ability to alter your choice. To acquire this additional information and the possibility to alter your route choice, you have to pay 6 Taler (see Fig. A.8; numerical values are fictitious). (You have $30 \mathrm{~s}$ to make your choice; otherwise, the question will automatically answered with "No".)

Only if you agree to above offer, the screen of Fig. A.9 appears (numerical values are fictitious). (You have $30 \mathrm{~s}$ to make your choice; otherwise, the original choice will automatically be confirmed.)

The following item was part of the instructions of experiment B.

- After you have made your route choice, you will receive information on how the other participants decided. Next, you have the ability to alter your choice (see Fig. A.9; numerical values are fictitious). (You have $30 \mathrm{~s}$ to make your choice; otherwise, the original choice will automatically be confirmed.)

Your travel expenses:

After each period the travel expenses are subtracted from your current balance. The travel expenses depend on two points:

\footnotetext{
${ }^{5}$ Depending on the experiment, the time to complete 50 periods varied. Therefore, we adapted the initial balance so that we could guarantee average hourly earnings of 12 euro.
} 


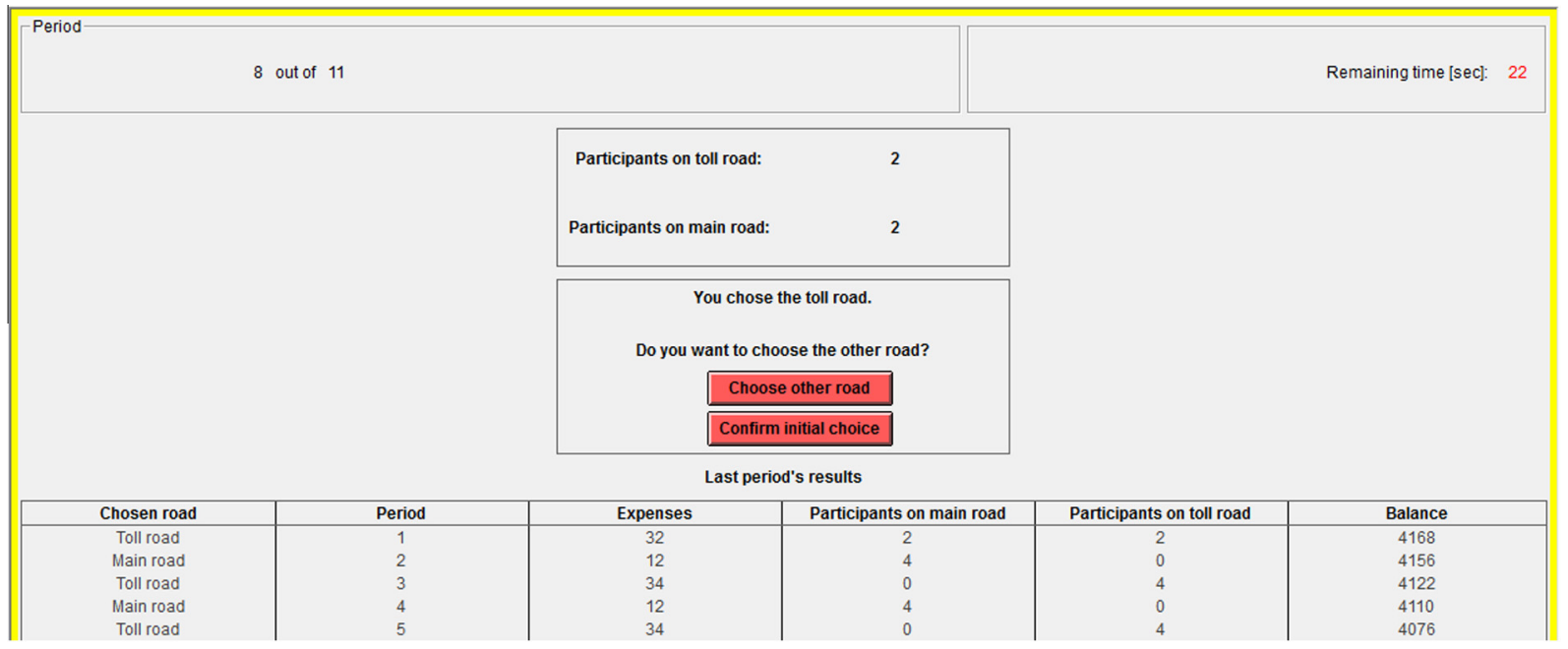

Fig. A.9. User screen showing the results of the intended road usage.

1. The more time you need to reach destination $B$, the higher are the travel expenses. This time depends on the number of participants choosing the same road as you. It holds: The less participants choose the same road as you, the lower are your travel expenses. (This is all information you get!)

2. If you choose the toll road, there are additional expenses of 30 Taler.

In each period you receive the following information about the previous periods in the lower part of the screen:

- the number of the period,

- the road you chose,

- your travel expenses for the corresponding period,

- the number of participants choosing the toll road and the main road, and

- your current balance.

\section{References}

Abdel-Aty, M. A., Kitamura, R., \& Jovanis, P. P. (1997). Using stated preference data for studying the effect of advanced traffic information on drivers' route choice. Transportation Research Part C, 5, 39-50. http://dx.doi.org/10.1016/S0968-090X(96)00023-X.

Adler, J. L. (2001). Investigating the learning effects of route guidance and traffic advisories on route choice behavior. Transportation Research Part C, 9, 1-14. http://dx.doi.org/10.1016/S0968-090X(00)00002-4.

Adler, J. L., \& McNally, M. G. (1994). In-laboratory experiments to investigate driver behavior under advanced traveler information systems. Transportation Research Part C, 2, 149-164. http://dx.doi.org/10.1016/0968-090X(94)90006-X.

Albert, G., Toledo, T., \& Ben-Zion, U. (2011). The role of personality factors in repeated route choice behavior: Behavioral economics perspective. European Transport, 47-59.

Arnott, R., de Palma, A., \& Lindsey, R. (1991). Does providing information to drivers reduce traffic congestion? Transportation Research Part A, 25, 309-318. http://dx.doi.org/10.1016/0191-2607(91)90146-H.

Belenky, P. (2011). Revised departmental guidance on valuation of travel time in economic analysis. Technical Report DOT HS 810 591. U.S. Department of Transportation, Washington, DC.

Ben-Akiva, M., De Palma, A., \& Isam, K. (1991). Dynamic network models and driver information systems. Transportation Research Part A, 25, 251-266. http:// dx.doi.org/10.1016/0191-2607(91)90142-D.

Brownstone, D., \& Small, K. A. (2005). Valuing time and reliability: Assessing the evidence from road pricing demonstrations. Transportation Research Part A, 39, 279-293. http://dx.doi.org/10.1016/j.tra.2004.11.001. connection Choice: Papers from the 10th IATBR Conference.

Cascetta, E., \& Cantarella, G. E. (1991). A day-to-day and within-day dynamic stochastic assignment model. Transportation Research Part A, 25, 277-291. http://dx.doi.org/10.1016/0191-2607(91)90144-F.

Cirillo, C., \& Axhausen, K. W. (2006). Evidence on the distribution of values of travel time savings from a six-week diary. Transportation Research Part A, 40, 444-457. http://dx.doi.org/10.1016/j.tra.2005.06.007.

Croson, R., \& Gneezy, U. (2009). Gender differences in preferences. Journal of Economic Literature, 47, 448-474. http://dx.doi.org/10.1257/jel.47.2.448.

de Palma, A., \& Lindsey, R. (2000). Private toll roads: Competition under various ownership regimes. Annals of Regional Science, 34, 13-35. http://dx.doi.org/ $10.1007 / \mathrm{s} 001680050124$

Emmerink, R. H. M., Axhausen, K. W., Nijkamp, P., \& Rietveld, P. (1995). Effects of information in road transport networks with recurrent congestion. Transportation, 22, 21-53. http://dx.doi.org/10.1007/BF01151617.

Emmerink, R. H. M., Nijkamp, P., Rietveld, P., \& van Ommeren, J. N. (1996). Variable message signs and radio traffic information: An integrated empirical analysis of drivers' route choice behaviour. Transportation Research Part A, 30, 135-153. http://dx.doi.org/10.1016/0965-8564(95)00016-X.

Fischbacher, U. (2007). z-tree: Zurich toolbox for ready-made economic experiments. Experimental Economics, 10, 171-178. http://dx.doi.org/10.1007/ s10683-006-9159-4.

Hall, F., Wakefield, S., \& Al-Kaisy, A. (2001). Freeway quality of service - what really matters to drivers and passengers? Transportation Research Record, 1776, 17-23. http://dx.doi.org/10.3141/1776-03. 
Helbing, D., Schönhof, M., \& Kern, D. (2002). Volatile decision dynamics: Experiments, stochastic description, intermittency control and traffic optimization. New Journal of Physics, 4, 33. http://dx.doi.org/10.1088/1367-2630/4/1/333.

Ieromonachou, P., Potter, S., \& Warren, J. P. (2006). Norway's urban toll rings: Evolving towards congestion charging? Transport Policy, 13, 367-378. http:// dx.doi.org/10.1016/j.tranpol.2006.01.003.

Iida, Y., Akiyama, T., \& Uchida, T. (1992). Experimental analysis of dynamic route choice behavior. Transportation Research Part B, 26, 17-32. http:// dx.doi.org/10.1016/0191-2615(92)90017-Q.

Jha, M., Madanat, S., \& Peeta, S. (1998). Perception updating and day-to-day travel choice dynamics in traffic networks with information provision. Transportation Research Part C, 6, 189-212. http://dx.doi.org/10.1016/S0968-090X(98)00015-1.

Kerner, B. S. (2004). The physics of traffic. Berlin: Springer. http://dx.doi.org/10.1007/978-3-540-40986-1_1.

Kerner, B. S. (2011). Optimum principle for a vehicular traffic network: Minimum probability of congestion. Journal of Physics A, 44, 092001. http:// dx.doi.org/10.1088/1751-8113/44/9/092001.

Kerner, B. S. (2013). Criticism of generally accepted fundamentals and methodologies of traffic and transportation theory: A brief review. Physica A, 392, 5261-5282. http://dx.doi.org/10.1016/j.physa.2013.06.004.

Kerner, B. S. (2014). Three-phase theory of city traffic: Moving synchronized flow patterns in under-saturated city traffic at signals. Physica A, 397, 76-110. http://dx.doi.org/10.1016/j.physa.2013.11.009.

Knorr, F., Baselt, D., Schreckenberg, M., \& Mauve, M. (2012). Reducing traffic jams via VANETs. IEEE Transactions on Vehicular Technology, 61, 3490-3498. http://dx.doi.org/10.1109/TVT.2012.2209690.

Kriger, D., Shiu, S., Naylor, S. (2006). Estimating toll road demand and revenue. National Cooperative Highway Research Program (NCHRP) synthesis, Transportation Research Board.

Lakas, A., \& Chaqfeh, M. (2010). A novel method for reducing road traffic congestion using vehicular communication. In Proc. 6th int. wireless communications and mobile computing conference (pp. 16-20). ACM. http://dx.doi.org/10.1145/1815396.1815401.

Lam, T. C., \& Small, K. A. (2001). The value of time and reliability: Measurement from a value pricing experiment. Transportation Research Part E, 37, $231-251$. http://dx.doi.org/10.1016/S1366-5545(00)00016-8. advances in the Valuation of Travel Time Savings.

Mahmassani, H. S., Caplice, C. G., \& Walton, M. C. (1990). Characteristics of urban commuter behavior: Switching propensity and use of information. Transportation Research Record, 1285, 57-69.

Mahmassani, H. S., Chang, G. L., \& Herman, R. (1986). Individual decisions and collective effects in a simulated traffic system. Transportation Science, 20, $258-271$.

Mahmassani, H. S., \& Jayakrishnan, R. (1991). System performance and user response under real-time information in a congested traffic corridor. Transportation Research Part A, 25, 293-307. http://dx.doi.org/10.1016/0191-2607(91)90145-G.

Mannering, F. L. (1989). Poisson analysis of commuter flexibility in changing routes and departure times. Transportation Research Part B, 23, 53-60. http:// dx.doi.org/10.1016/0191-2615(89)90023-4.

Mannering, F., Kim, S. G., Barfield, W., \& Ng, L. (1994). Statistical analysis of commuters' route, mode, and departure time flexibility. Transportation Research Part C, 2, 35-47. http://dx.doi.org/10.1016/0968-090X(94)90018-3.

Meneguzzer, C., \& Olivieri, A. (2013). Day-to-day traffic dynamics: Laboratory-like experiment on route choice and route switching in a simple network with limited feedback information. Procedia - Social and Behavioral Sciences, 87, 44-59. http://dx.doi.org/10.1016/j.sbspro.2013.10.593. SIDT Scientific Seminar 2012 .

Nakayama, S., \& Kitamura, R. (2001). Route choice model with inductive learning. Transportation Research Record, 1725, 63-70. http://dx.doi.org/10.3141/ 1725-09.

Nelson, J., 2012. Are Women Really More Risk-Averse than Men? GDAE Working Papers 12-05. GDAE, Tufts University.

Noland, R. B. (1997). Commuter responses to travel time uncertainty under congested conditions: Expected costs and the provision of information. Journal of Urban Economics, 41, 377-406. http://dx.doi.org/10.1006/juec.1996.2006.

Ozbay, K., Datta, A., \& Kachroo, P. (2001). Modeling route choice behavior with stochastic learning automata. Transportation Research Record, $1752,38-46$. http://dx.doi.org/10.3141/1752-06.

Papinski, D., Scott, D. M., \& Doherty, S. T. (2009). Exploring the route choice decision-making process: A comparison of planned and observed routes obtained using person-based gps. Transportation Research Part F, 12, 347-358. http://dx.doi.org/10.1016/j.trf.2009.04.001.

Schofer, J. L., Khattak, A., \& Koppelman, F. S. (1993). Behavioral issues in the design and evaluation of advanced traveler information systems. Transportation Research Part C, 1, 107-117. http://dx.doi.org/10.1016/0968-090X(93)90008-4.

Schrank, D., Lomax, T., Eisele, B. (2011). Urban mobility report 2011. Texas Transportation Institute, The Texas A\&M University System.

Selten, R., Chmura, T., Pitz, T., Kube, S., \& Schreckenberg, M. (2007). Commuters route choice behaviour. Games and Economic Behavior, 58, 394-406. http:// dx.doi.org/10.1016/j.geb.2006.03.012.

Selten, R., Schreckenberg, M., Pitz, T., Chmura, T., \& Wahle, J. (2003). Experiments on route choice behaviour. In H. Emmerich, B. Nestler, \& M. Schreckenberg (Eds.), Interface and transport dynamics. Lecture notes in computational science and engineering (vol. 32, pp. 317-321). Berlin Heidelberg: Springer. http:// dx.doi.org/10.1007/978-3-662-07969-0_30.

Singh, R., Dowling, R. (1999). Improved speed-flow relationships: Application to transportation planning models. In: R. Donnelly (Ed.), Proceedings of the seventh TRB conference on the application of transportation planning methods. Transportation Research Board, pp. 340-349.

Small, K. A., Gomez-Ilbanez, J. A. (1998). Road pricing for congestion management: The transition from theory to policy. University of California Transportation Center, Working Papers 391. University of California Transportation Center.

Small, K. A., Noland, R., Chu, X., Lewis, D. (1999). Valuation of travel-time savings and predictability in congested conditions for highway user-cost estimation. Number 431 in National Cooperative Highway Research Program (NCHRP) Report, National Academy Press.

Victoria Transport Policy Institute. (2014). Transportation elasticities; how prices and other factors affect travel behaviour. <http://www.vtpi.org/tdm/ tdm11.htm\#_Toc18128471>.

Wardrop, J. G. (1952). Some theoretical aspects of road traffic research. ICE Proceedings: Engineering Divisions, 1, 325-362. http://dx.doi.org/10.1680/ ipeds.1952.11259.

Yang, H., Kitamura, R., Jovanis, P. P., Vaughn, K., \& Abdel-Aty, M. (1993). Exploration of route choice behavior with advanced traveler information using neural network concepts. Transportation, 20, 199-223. http://dx.doi.org/10.1007/BF01307059.

Zhang, L., \& Levinson, D. M. (2008). Determinants of route choice and value of traveler information: A field experiment. Transportation Research Record, 2086, 81-92. http://dx.doi.org/10.3141/2086-10. 